\title{
A review on the diagnosis and treatment of hepatocellular carcinoma with a focus on the role of Wnts and the dickkopf family of Wnt inhibitors
}

This article was published in the following Dove Press journal:

Journal of Hepatocellular Carcinoma

6 March 2014

Number of times this article has been viewed

\author{
Junlin Shi ${ }^{1,2}$ \\ jill M Keller ${ }^{3}$ \\ Jian Zhang ${ }^{1,2}$ \\ Evan T Keller ${ }^{1-3}$ \\ 'Key Laboratory of Longevity and \\ Ageing-Related Diseases, Ministry \\ of Education, Nanning, Guangxi, \\ People's Republic of China; ${ }^{2}$ Center \\ for Translational Medicine, Guangxi \\ Medical University, Nanning, \\ Guangxi, People's Republic of China; \\ ${ }^{3}$ Department of Urology, School of \\ Medicine, University of Michigan, Ann \\ Arbor, MI, USA
}

\begin{abstract}
Hepatocellular carcinoma (HCC) is one of the most prevalent cancers worldwide. There are multiple etiologic factors including viral and environmental influences that can lead to HCC. Successful screening for early HCC is challenging due to the lack of well characterized and specific biomarkers. However, achieving successful screening is critically important as early diagnosis can potentially provide curative opportunities. Once HCC is advanced, there are multiple therapeutic venues, but most eventually fail, therefore developing new targeted therapies may provide greater chance for effective therapies. Along these lines, the Wnt pathway has been identified as contributing to the development and progression of HCC. Wnts can modify HCC growth and invasive ability. A key factor in the Wnt pathway is the dickkopf (DKK) family of Wnt inhibitors. DKKs have also been shown to modulate HCC progression. Additionally, several studies have suggested that DKK expression in tissue and serum has diagnostic and prognostic value.

Keywords: hepatoma, DKK, beta-catenin, morphogen, biomarker
\end{abstract}

\section{Epidemiology}

Primary liver cancer is the fifth most common cancer and the third most common cause of cancer related deaths worldwide. Hepatocellular carcinoma (HCC) accounts for $85 \%$ to $90 \%$ of primary liver cancers and it is one of the most prevalent malignant tumors worldwide. ${ }^{1,2}$

Causes for HCC are multifactorial. Its development is a multistep and complex process. HCC has several interesting epidemiologic features, such as dynamic temporal trends, geographic regions, racial and ethnic groups, gender bias, and the presence of several well documented environmental and potentially preventable risk factors. Among approximately 650,000 people who die from HCC each year, at least two thirds live in Asia. ${ }^{3}$ The People's Republic of China alone accounts for more than $50 \%$ of the world's cases. ${ }^{4}$ Men are two to four times more often associated with HCC than women. It has been suggested that sex hormones including progesterone may play a part in HCC. ${ }^{5}$ Major risk factors for HCC include hepatitis B virus (HBV) or hepatitis $\mathrm{C}$ virus infection, alcoholic liver disease, nonalcoholic fatty liver disease, and aflatoxin B1 intake.

\section{Diagnosis}

Due to its asymptomatic nature HCC is usually diagnosed at late and advanced stages, for which there are no effective therapies. The diagnosis of HCC in the early stage is crucial to the application of curative treatments, and currently it is the only hope for increasing the life expectancy of patients. At present, the combination of ultrasound
Correspondence: Evan T Keller University of Michigan, Room 5308 Cancer Center, 1500 East Medical Center Dr, Ann Arbor, MI 48I05, USA Email etkeller@umich.edu 
and measurement of $\alpha$-fetoprotein (AFP) are widely accepted and implemented as a screening strategy. Although this combination approach offers an increased possibility to detect small HCC compared to ultrasound or AFP measurement alone, ${ }^{6-8}$ it is insensitive. Serum AFP level is a useful tumor marker for the detection and monitoring of $\mathrm{HCC}$, but the false negative rate may be as high as $40 \%$ for patients with early stage HCC. Even in patients with advanced HCC, the AFP levels may remain regular in $15 \%-30 \%$ of patients. ${ }^{9}$ Therefore, biomarkers for early detection and molecular targets for treating HCC are urgently needed.

Over the past few decades, screening for and early diagnosis of HCC has attracted worldwide attention, especially in Asian countries including Japan and the People's Republic of China. ${ }^{10}$ Several high throughput studies have thrown light on this problem by employing genomics, proteomics, and transcriptomics to detect markers correlated with HCC progression. Ju et al found that a type II Golgi-specific membrane protein, Golgi phosphoprotein 2, was overexpressed in $\mathrm{HCC}$ patients and it was more sensitive for diagnosis of $\mathrm{HCC}$ (76\%) than the traditional biomarker AFP (70\%). ${ }^{11}$ Therefore, Golgi phosphoprotein 2 may be a new and effective serum biomarker for HCC diagnosis. Youns et at described that talin-1 has the potential to serve as an important prognostic marker for the diagnosis of HCC, with superior sensitivity and specificity when compared to AFP. ${ }^{12} \mathrm{Xia}$ et al reported that sperm protein 17 is highly expressed in HCC cells and that its diagnostic significance is that sperm protein 17 expression frequency is associated with the pathologic differentiation in $\mathrm{HCC} .{ }^{13} \mathrm{Xu}$ et al state that high temperature requirement protein $\mathrm{A} 2$ (Omi/HtrA2) may be a useful HCC diagnostic marker because it is expressed in apoptotic HCC cells. ${ }^{14}$ Hou et al report that serum Golgi protein 73 levels were significantly higher in HCC patients when compared to individuals with benign liver diseases. ${ }^{15}$ Therefore, it has the potential to be an independent diagnostic candidate for HCC. It has been suggested that the diagnostic efficiency of HCC may be increased by determining the expression of serum golgi protein 73, AFP, and gamma glutamyltransferase II (GGT-II) in combination. ${ }^{15} \mathrm{Zhu}$ et al also combined detected GGT-II with AFU or AFP, and found that this approach exhibited higher sensitivity and specificity for HCC diagnosis. ${ }^{16}$ Sieghart et al investigated the prognostic value of C-reactive protein in HCC patients who were not amenable to surgery and found that $\mathrm{C}$-reactive protein over expression is closely related to dismal prognosis of HCC patients and it may become a potential marker for patient selection in $\mathrm{HCC}$ management. ${ }^{17}$
There also are other methods for biomarker detection. Taleb et al reported that serum micro-Raman spectroscopy may serve as a diagnostic tool for cancer biomarker detection. ${ }^{18}$ Tanaka et al detected serum des-gamma-carboxy prothrombin (DCP) levels through a newly developed electrochemiluminescence immunoassay (novel DCP [NX$\mathrm{DCP}]$ ) and found that the DCP/NX-DCP ratio is very useful for diagnosing HCC. ${ }^{19}$ Moreover, large scale metabolomic technologies have been widely applied to discover candidate biomarkers for cancer staging, recurrence and prognosis prediction, and treatment selection. Wang et al also stated the usefulness of metabolic profiles in $\mathrm{HCC}^{20}$ Zhang et al combined differential gene expression with topological features of human protein networks to develop a system biology based classifier which may enhance the ability of HCC diagnosis. ${ }^{21}$

\section{Treatment}

$\mathrm{HCC}$ is a highly malignant tumor with limited treatment options for advanced disease. Treatment regimens include resection, radiofrequency ablation, percutaneous ethanol injection, transcatheter arterial chemoembolization, transarterial oily chemoembolization, hepatic arterial infusion chemotherapy, or systemic therapy including chemotherapy and molecular targeting. Several excellent reviews on the many treatment modalities have recently been published. ${ }^{22-24}$ Treatments may be used alone or in combination with a clinical goal of striking the best balance between functional hepatic reserve and the volume of the targeted area. ${ }^{25}$

Less than $30 \%$ of patients with HCC are eligible for surgery, but when applicable, surgery is the most efficient treatment for HCC. ${ }^{26-28}$ Progress in the ability to perform hepatic function assessment, understand segmental liver anatomy, obtain optimal imaging, and enhanced surgical techniques have led to reduce $\mathrm{HCC}$ mortality resulting in a 5-year survival rate of $70 \% .{ }^{29}$ Liver transplantation was thought to be an ideal treatment for HCC patients (reviewed by Lee Cheah and $\mathrm{KH}$ Chow $^{23}$ ) who fit within the Milan staging criteria (classically a single nodule $<5 \mathrm{~cm}$ or two or three nodules $<3 \mathrm{~cm}$, reviewed in Jarnagin ${ }^{30}$ ). However, the limited availability of grafts, the risk and the cost of the liver transplantation procedure create challenges to this strategy. ${ }^{31,32}$

Many nonsurgical treatments of HCC have significantly improved in the last few decades and have shown survival benefits for selected patients with HCC. Patients who were diagnosed in the early stage benefit from ablation which may offer curative treatment. Intermediate stage HCC patients benefit from transarterial chemoembolization. Compared with 
conventional transarterial chemoembolization, drug-eluting bead transarterial chemoembolization has a better combination of ischemic and cytotoxic effect locally and less system toxicity. Those diagnosed at advanced stage benefit from the multi tyrosine and Raf kinase inhibitor, sorafenib. ${ }^{33}$ The blood neutrophil-to-lymphocyte ratio offers prognostic significance for patients with advanced HCC who receive sorafenib monotherapy. ${ }^{34}$ Many other targeted therapies are under development for HCC and the future holds promise for novel strategies.

\section{Signaling}

In $\mathrm{HCC}$, signaling pathways have been a major source of targets for novel therapies. Numerous biological pathways are deregulated in $\mathrm{HCC}$, such as cell differentiation and development signaling pathways, cell proliferation signaling pathways, angiogenesis signaling pathways, and some other signaling pathways.

\section{Cell differentiation and development signaling pathways}

Upon hepatic damage, the Hedgehog signaling pathway promotes hepatic regeneration; however, excessive or continuous activation of Hedgehog has been shown to halt successful regeneration and contribute to liver fibrosis. ${ }^{35}$ The Hippo signaling pathway appears to have an oncogenic role in many human cancers, including $\mathrm{HCC} .{ }^{36}$ Consistent with a role for Hippo in HCC are the reports that inhibition of YAP (a downstream mediator of Hippo signaling) by MST1/2 (forms an initial Hippo kinase complex) can suppress HCC. ${ }^{37,38}$ Finally, in the liver, significant overexpression of NOTCH1 and NOTCH3 was detected through immunohistochemistry in $60 \mathrm{HCCs}$ and experiments suggested that NOTCH3 silencing in combination with chemotherapeutics could conceivably provide a novel strategy for HCC treatment. ${ }^{39}$ In addition, considering the important role of $\mathrm{HBV} X$ protein in the development of $\mathrm{HCC}$, a recent study suggests that NOTCH activation may be one of the mechanisms by which HBV X protein promotes HCC progression. ${ }^{40}$

\section{Cell proliferation signaling pathways}

Epidermal growth factor (EGF) receptor signaling has been shown to be present in $\mathrm{HCC}$, with overexpression at both mRNA and protein levels. ${ }^{41}$ Deregulation of EGF in cirrhotic tissue seems to impact HCC development, as shown in a gene signature able to predict prognosis in surgically resected $\mathrm{HCC}$ patients. ${ }^{42}$ Moreover, a specific single nucleotide polymorphism in the $E G F$ gene, which increases ligand half-life, correlated with the risk of $\mathrm{HCC}$ development. ${ }^{43}$ Tovar et al reported selective blockade of insulin-like growth factor signaling had antitumor effects in experimental models of $\mathrm{HCC}^{44}$ In Ras/mitogen-activated protein kinase (MAPK) and Akt/phosphatidylinositide 3-kinase (PI3K)/mammalian target of rapamycin (mTOR) pathways, the Ras cascade is of special importance because it is one of the main targets of sorafenib, the only systematic therapy currently effective for advanced HCC. ${ }^{45}$ Moreover, in resected HCCs, activated Akt correlates with increased recurrence risk of this cancer. ${ }^{46}$ In fact, mTOR inhibitors such as everolimus are being tested in advanced clinical trials as first and second line therapy for HCC.${ }^{47}$ In addition, Wang et al found that Wnt/ $\beta$-catenin, Ras/ MAPK, and PI3K/AKT signaling pathways form a complex network and play important roles during HCC genesis and development. ${ }^{48}$

\section{Wnts and the Wnt inhibitor Dickkopf in HCC}

Wnts are cysteine-rich glycoproteins involved in multiple biological processes. Canonical Wnt signaling is summarized in Figure 1. Briefly, in the absence of Wnts, $\beta$-catenin, which serves as transcriptional coactivator, is ubiquitinated by a protein complex that consists of adenomatous polyposis coli, axin, and glycogen synthase kinase $3 \beta$. Ubiquitination targets $\beta$-catenin for degradation. When present, Wnts bind their receptor complex, which may consist of several different proteins including frizzled, low-density lipoprotein receptor-related protein, and kremen. Activation of the receptor complex results in breakdown of the $\beta$-catenin degradation complex which allows for accumulation of $\beta$-catenin which translocates to the nucleus and promotes transcription of target genes. DKKs are endogenous inhibitors of Wnts. They achieve this activity through blocking low-density lipoprotein receptor-related protein binding to the kremen coreceptor.

The Wnt signaling pathway has a close relationship with HCC. A recent study showed two different patterns of Wnt activation in HCC and a potential Wnt blockade effect of sorafenib in experimental models. ${ }^{49}$ Sorafenib modulates Wnt $/ \beta$-catenin signaling in experimental models that harbor the CTNNB1 class signature. ${ }^{49}$ Wei et al demonstrated that sorafenib sensitizes human $\mathrm{HCC}$ cells to cisplatin by suppression of $\mathrm{Wnt} / \beta$-catenin signaling, thus offering a new target for chemotherapy of HCC. ${ }^{50}$ Lachenmayer et al reported that distinct dysregulation of Wnt pathway constituents characterize two different Wnt-related molecular classes (CTNNB1 and Wnt-transforming growth factor beta), accounting for half of all HCC patients. ${ }^{49}$ 
A
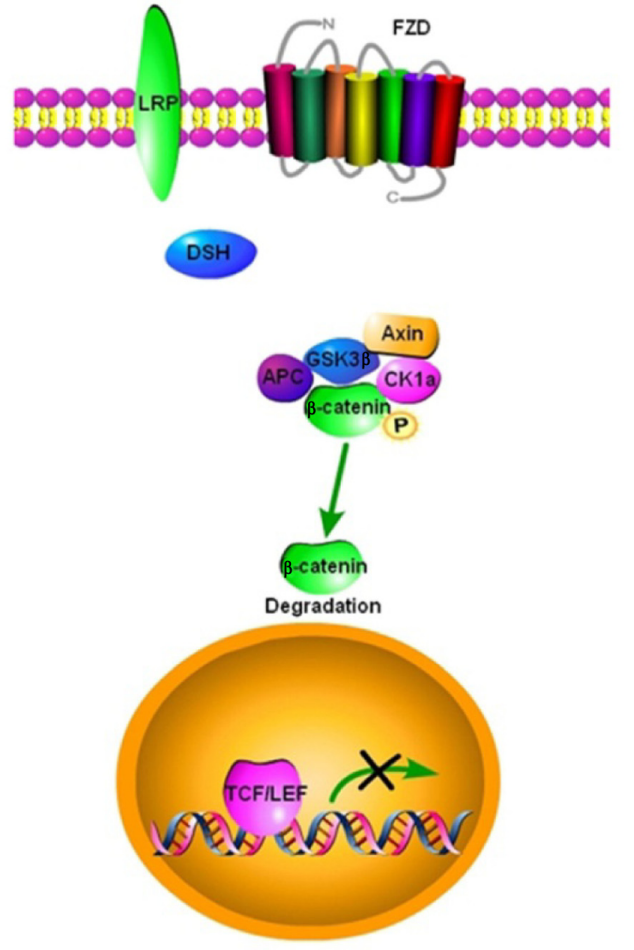

B
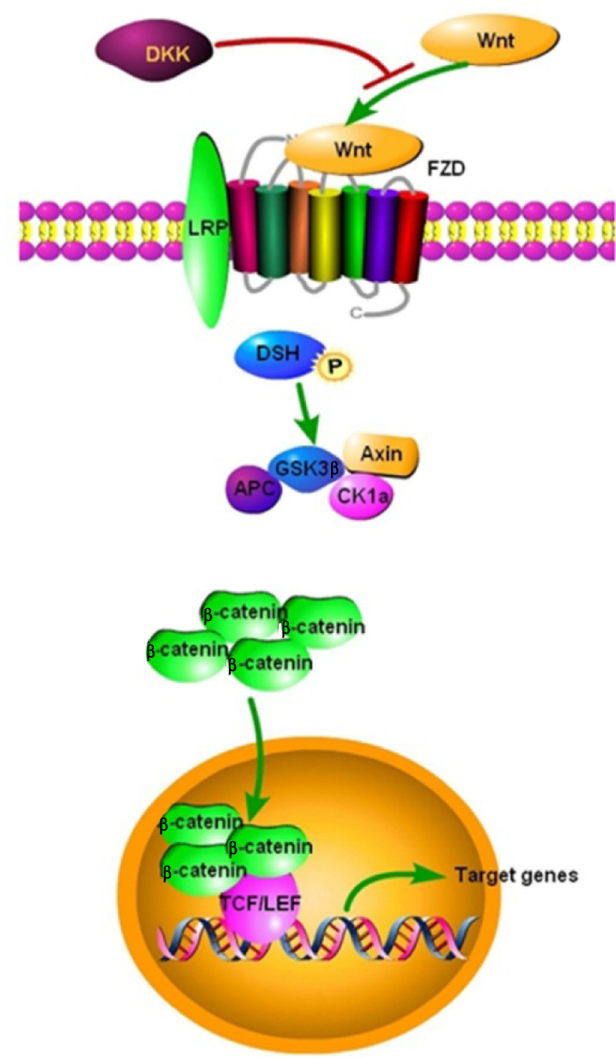

Figure I Wnt signaling pathway.

Notes: (A) In the absence of Wnts, $\beta$-catenin is ubiquitinated and targeted for degradation by a protein complex that consists of adenomatous polyposis coli, axin, and glycogen synthase kinase $3 \beta$. (B) Wnts bind their receptor complex, which may consist of several different proteins including frizzled, low-density lipoprotein receptor-related protein, and kremen. Activation of the receptor complex results in breakdown of the $\beta$-catenin degradation complex and accumulation of $\beta$-catenin which translocates to the nucleus and promotes transcription of target genes. Dickkopfs can block Wnt signaling through inhibiting low-density lipoprotein receptor-related protein activity.

Abbreviations: APC, adenomatous polyposis coli; CKIa, casein kinase la; DKK, Dickkopf; DSH, disheveled; FZD, frizzled; GSK3 $\beta$, glycogen synthase kinase 3 $\beta$; LRP, lowdensity lipoprotein receptor-related protein; P, phosphate; TCF/LEF, T-cell factor/lymphoid-enhancing factor.

Wnt signaling pathways relate to cell differentiation and development. Numerous studies show that the Wnt/ $\beta$ catenin pathway is a therapeutic target in human HCC. ${ }^{51} \mathrm{Xu}$ et al reported that curcumin suppresses proliferation and induces apoptosis of $\mathrm{HCC}$ cells through the Wnt signaling pathway. ${ }^{52} \mathrm{Li}$ et al demonstrated that the gene promoter of cysteine-rich angiogenic inducer 61 (Cyr61), a matricellular protein that promotes HCC progression, is activated by $\beta$-catenin in HCC. ${ }^{53}$ This report conflicts with an earlier study that suggested Cyr61 is a tumor suppressor for HCC. ${ }^{54}$ A potential explanation for the difference could be the timing of the Cyr61 expression. Specifically, there is the potential that it may have tumor suppressor function prior to tumor development, but once a tumor is developed, it may enhance progression. Liu et al reported that enhancement of canonical Wnt/ $\beta$-catenin signaling activity by HCV core protein promotes cell growth of HCC cells. ${ }^{55}$ Based on two parallel cell lines, Tsao et al found that SOX1 functions as a tumor suppressor by antagonizing the Wnt/ $/$-catenin signaling pathway in HCC. ${ }^{56}$ Yang et al testified that kruppel-like factor 8 is a new Wnt/ $\beta$-catenin signaling target gene and regulator in $\mathrm{HCC} .{ }^{57} \mathrm{Xu}$ et al reported that microRNA-122 suppresses cell proliferation and induces cell apoptosis in $\mathrm{HCC}$ by directly targeting the Wnt/ $\beta$-catenin pathway. ${ }^{58}$ Wolfe et al reported that dapper, a disheveled-associated antagonist of $\beta$-catenin homolog $2,{ }^{59}$ increased $\mathrm{Wnt} / \beta$-catenin pathway activation in spontaneous HCC observed in farnesoid X receptor knockout mice. ${ }^{60}$ Kaur et al found that epigenetic silencing of secreted frizzled-related protein 1 activates the canonical Wnt pathway and contributes to increased cell growth and proliferation in $\mathrm{HCC} .{ }^{61}$

In addition to Wnts themselves, DKKs impact HCC pathobiology. Qin et al investigated the role of DKK1 and $\mathrm{Wnt} / \beta$-catenin pathway in proliferation and migration of HCC cells. ${ }^{62}$ They compared a cell line and a metastatic variant of the cell line and found that $\beta$-catenin was upregulated 
and that DKK1 was downregulated in the metastatic variant. Furthermore, ectopic expression of DKK1 in the metastatic line reduced its invasive and proliferative activity. These results were consistent with a previous study that reported overexpression of DKK1 in HCC cells decreased cell growth and increased the number of cells in sub-G1. ${ }^{63}$ Similar results were found by Fatima et al for DKK4 in HCC. ${ }^{64}$ Specifically, ectopic expression of DKK4 in HCC cell lines reduced their invasive and proliferative ability in vitro, as well as their tumor growth in vivo in murine models. These results provide molecular evidence that DKKs, through inhibition of Wnt signaling, can inhibit HCC progression.

Due to the importance of regulating the Wnt pathway in HCC, several investigators have evaluated the ability of DKK to serve as a biomarker. Several reports suggest that DKK3 promoter methylation is upregulated in HCC versus nonneoplastic hepatic tissue and that its methylation is associated with a poor prognosis. ${ }^{65,66}$ Tao et al found that DKK1 was elevated in clinical HCC tissues, especially in tissue with vascular invasion. ${ }^{67}$ Increased DKK1 expression was correlated with poor overall and disease-free survival suggesting that DKK1 could serve as a novel prognostic marker for HCC. ${ }^{67}$ In order to extend the diagnostic utility of DKKs, serum levels of DKK in HCC have been evaluated suggesting that they are a cancer specific serum biomarker for various human cancers. ${ }^{68}$ Shen et al, in a large multiinstitutional trial, determined that elevated serum DKK1 levels could differentiate HCC from chronic HBV infection and cirrhosis. ${ }^{69}$ Moreover, measurement of DKK1 and AFP together improved diagnostic accuracy for HCC versus all controls compared with either test alone. Yang et al compared the serum of patients with early HCC to serum from healthy individuals or patients with nonmalignant hepatic disease (cirrhosis or benign tumors) for DKK1 and AFP. ${ }^{70}$ Serum DKK1 expression was elevated in early HCC patients compared to all other groups. DKK1 also had better sensitivity and accuracy than AFP for diagnosis of HCC including the ability to identify the presence of $\mathrm{HCC}$ in those patients who were AFP negative. Serum DKK1 expression was also correlated with poorer overall prognosis and relapse-free survival. Overall these data suggest that DKK1 can serve as a diagnostic and prognostic serologic marker for early HCC. It should be noted that these results are unexpected based on earlier studies in which DKK expression is downregulated due to promoter methylation and the expected activation of the Wnt pathway that promotes HCC. Additional prospective studies to determine the validity of DKKs as biomarkers of HCC are warranted.

\section{Acknowledgments}

This work was supported by National Institutes of Health Grant P01 CA093900, National Natural Science Foundation of China 81171993 and 81272415, and Key Program of National Natural Science Foundation of China 81130046.

\section{Disclosure}

The authors report no conflict of interest in this work.

\section{References}

1. Wei Q, Mu K, Li T, Zhang Y, et al. Deregulation of the NLRP3 inflammasome in hepatic parenchymal cells during liver cancer progression. Lab Invest. 2014;94(1):52-62.

2. Zhu XL, Wang YL, Chen JP, et al. Alternol inhibits migration and invasion of human hepatocellular carcinoma cells by targeting epithelial-to-mesenchymal transition. Tumour Biol. Epub September 29, 2013.

3. Asia-Pacific Working Party on Prevention of Hepatocellular Carcinoma. Prevention of hepatocellular carcinoma in the Asia-Pacific region: consensus statements. J Gastroenterol Hepatol. 2010;25(4): 657-663.

4. El-Serag HB, Rudolph KL. Hepatocellular carcinoma: epidemiology and molecular carcinogenesis. Gastroenterology. 2007;132(7): 2557-2576.

5. Yeh YT, Chang CW, Wei RJ, Wang SN. Progesterone and related compounds in hepatocellular carcinoma: basic and clinical aspects. Biomed Res Int. 2013;2013:290575.

6. McMahon BJ, Bulkow L, Harpster A, et al. Screening for hepatocellular carcinoma in Alaska natives infected with chronic hepatitis B: a 16-year population-based study. Hepatology. 2000;32(4 Pt 1):842-846.

7. Toyoda H, Kumada T, Kiriyama S, et al. Impact of surveillance on survival of patients with initial hepatocellular carcinoma: a study from Japan. Clin Gastroenterol Hepatol. 2006;4(9):1170-1176.

8. Thompson Coon J, Rogers G, Hewson P, et al. Surveillance of cirrhosis for hepatocellular carcinoma: systematic review and economic analysis. Health Technol Assess. 2007;11(34):1-206.

9. Volk ML, Hernandez JC, Su GL, Lok AS, Marrero JA. Risk factors for hepatocellular carcinoma may impair the performance of biomarkers: a comparison of AFP, DCP, and AFP-L3. Cancer Biomark. 2007;3(2): 79-87.

10. Song P, Gao J, Inagaki Y, et al. Biomarkers: evaluation of screening for and early diagnosis of hepatocellular carcinoma in Japan and China. Liver cancer. 2013;2(1):31-39.

11. Ju Q, Zhao Y, Liu Y, et al. Monoclonal antibody preparation of Golgi phosphoprotein 2 and preliminary application in the early diagnosis of hepatocellular carcinoma. Mol Med Rep. 2013;8(2):517-522.

12. Youns MM, Abdel Wahab AH, Hassan ZA, Attia MS. Serum talin-1 is a potential novel biomarker for diagnosis of hepatocellular carcinoma in Egyptian patients. Asian Pac J Cancer Prev. 2013;14(6):3819-3823.

13. Xia QY, Liu S, Li FQ, Huang WB, Shi LN, Zhou XJ. Sperm protein 17, MAGE-C1 and NY-ESO-1 in hepatocellular carcinoma: expression frequency and their correlation with clinical parameters. Int J Clin Exp Pathol. 2013;6(8):1610-1616.

14. Xu Z, Chen X, Peng C, et al. The expression and clinical significance of Omi/Htra2 in hepatocellular carcinoma. Hepatogastroenterology. 2013;60(121):6-13.

15. Hou SC, Xiao MB, Ni RZ, et al. Serum GP73 is complementary to AFP and GGT-II for the diagnosis of hepatocellular carcinoma. Oncol Lett. 2013;6(4):1152-1158.

16. Zhu J, Jiang F, Ni HB, et al. Combined analysis of serum gammaglutamyl transferase isoenzyme II, alpha-L-fucosidase and alphafetoprotein detected using a commercial kit in the diagnosis of hepatocellular carcinoma. Exp Ther Med. 2013;5(1):89-94. 
17. Sieghart W, Pinter M, Hucke F, et al. Single determination of $\mathrm{C}$-reactive protein at the time of diagnosis predicts long-term outcome of patients with hepatocellular carcinoma. Hepatology. 2013;57(6): 2224-2234.

18. Taleb I, Thiefin G, Gobinet C, et al. Diagnosis of hepatocellular carcinoma in cirrhotic patients: a proof-of-concept study using serum micro-Raman spectroscopy. Analyst. 2013;138(14):4006-4014.

19. Tanaka T, Taniguchi T, Sannomiya K, et al. Novel des-gamma-carboxy prothrombin in serum for the diagnosis of hepatocellular carcinoma. J Gastroenterol Hepatol. 2013;28(8):1348-1355.

20. Wang X, Zhang A, Sun H. Power of metabolomics in diagnosis and biomarker discovery of hepatocellular carcinoma. Hepatology. 2013;57(5):2072-2077.

21. Zhang Y, Wang S, Li D, et al. A systems biology-based classifier for hepatocellular carcinoma diagnosis. PloS One. 2011;6(7):e22426.

22. Kudo M. Treatment of advanced hepatocellular carcinoma with emphasis on hepatic arterial infusion chemotherapy and molecular targeted therapy. Liver Cancer. 2012;1(2):62-70.

23. Lee Cheah Y, KH Chow P. Liver transplantation for hepatocellular carcinoma: an appraisal of current controversies. Liver Cancer. 2012;1(3-4):183-189.

24. Lin S, Hoffmann K, Schemmer P. Treatment of hepatocellular carcinoma: a systematic review. Liver Cancer. 2012;1(3-4):144-158.

25. Suda T, Nagashima A, Takahashi S, et al. Active treatments are a rational approach for hepatocellular carcinoma in elderly patients. World $J$ Gastroenterol. 2013;19(24):3831-3840.

26. El-Serag HB, Marrero JA, Rudolph L, Reddy KR. Diagnosis and treatment of hepatocellular carcinoma. Gastroenterology. 2008;134(6): 1752-1763

27. Llovet JM, Burroughs A, Bruix J. Hepatocellular carcinoma. Lancet. 2003;362(9399):1907-1917.

28. Forner A, Reig ME, de Lope CR, Bruix J. Current strategy for staging and treatment: the BCLC update and future prospects. Semin Liver Dis. 2010;30(1):61-74.

29. Eguchi S, Kanematsu T, Arii S, et al. Recurrence-free survival more than 10 years after liver resection for hepatocellular carcinoma. $\mathrm{Br} J$ Surg. 2011;98(4):552-557.

30. Jarnagin WR. Management of small hepatocellular carcinoma: a review of transplantation, resection, and ablation. Ann Surg Oncol. 2010;17(5):1226-1233.

31. Cucchetti A, Vitale A, Gaudio MD, et al. Harm and benefits of primary liver resection and salvage transplantation for hepatocellular carcinoma. Am J Transplant. 2010;10(3):619-627.

32. Fuks D, Dokmak S, Paradis V, Diouf M, Durand F, Belghiti J. Benefit of initial resection of hepatocellular carcinoma followed by transplantation in case of recurrence: an intention-to-treat analysis. Hepatology. 2012;55(1):132-140.

33. Cheng JW, Lv Y. New progress of non-surgical treatments for hepatocellular carcinoma. Med Oncol. 2013;30(1):381.

34. Zheng YB, Zhao W, Liu B, et al. The blood neutrophil-to-lymphocyte ratio predicts survival in patients with advanced hepatocellular carcinoma receiving sorafenib. Asian Pac J Cancer Prev. 2013;14(9): 5527-5531.

35. Omenetti A, Choi S, Michelotti G, Diehl AM. Hedgehog signaling in the liver. J Hepatol. 2011;54(2):366-373.

36. Chan SW, Lim CJ, Chen L, et al. The Hippo pathway in biological control and cancer development. J Cell Physiol. 2011;226(4):928-939.

37. Lu L, Li Y, Kim SM, et al. Hippo signaling is a potent in vivo growth and tumor suppressor pathway in the mammalian liver. Proc Natl Acad Sci US A. 2010;107(4):1437-1442.

38. Song H, Mak KK, Topol L, et al. Mammalian Mst1 and Mst2 kinases play essential roles in organ size control and tumor suppression. Proc Natl Acad Sci U S A. 2010;107(4):1431-1436.

39. Giovannini C, Gramantieri L, Chieco P, et al. Selective ablation of Notch3 in HCC enhances doxorubicin's death promoting effect by a p53 dependent mechanism. J Hepatol. 2009;50(5):969-979.
40. Wang F, Zhou H, Yang Y, et al. Hepatitis B virus X protein promotes the growth of hepatocellular carcinoma by modulation of the Notch signaling pathway. Oncol Rep. 2012;27(4):1170-1176.

41. Villanueva A, Chiang DY, Newell P, et al. Pivotal role of mTOR signaling in hepatocellular carcinoma. Gastroenterology. 2008;135(6): 1972-1983.

42. Hoshida Y, Villanueva A, Kobayashi M, et al. Gene expression in fixed tissues and outcome in hepatocellular carcinoma. $N$ Engl J Med. 2008;359(19):1995-2004.

43. Tanabe KK, Lemoine A, Finkelstein DM, et al. Epidermal growth factor gene functional polymorphism and the risk of hepatocellular carcinoma in patients with cirrhosis. JAMA. 2008;299(1):53-60.

44. Tovar V, Alsinet C, Villanueva A, et al. IGF activation in a molecular subclass of hepatocellular carcinoma and pre-clinical efficacy of IGF-1R blockage. J Hepatol. 2010;52(4):550-559.

45. Villanueva A, Llovet JM. Targeted therapies for hepatocellular carcinoma. Gastroenterology. 2011;140(5):1410-1426.

46. Nakanishi K, Sakamoto M, Yamasaki S, Todo S, Hirohashi S. Akt phosphorylation is a risk factor for early disease recurrence and poor prognosis in hepatocellular carcinoma. Cancer. 2005;103(2):307-312.

47. Worns MA. Systemic therapy and synergies by combination. Dig Dis. 2013;31(1):104-111.

48. Wang XH, Meng XW, Sun X, et al. Wnt/beta-catenin signaling regulates MAPK and Akt1 expression and growth of hepatocellular carcinoma cells. Neoplasma. 2011;58(3):239-244.

49. Lachenmayer A, Alsinet C, Savic R, et al. Wnt-pathway activation in two molecular classes of hepatocellular carcinoma and experimental modulation by sorafenib. Clin Cancer Res. 2012;18(18):4997-5007.

50. Wei Y, Shen N, Wang Z, et al. Sorafenib sensitizes hepatocellular carcinoma cell to cisplatin via suppression of $\mathrm{Wnt} / \beta$-catenin signaling. Mol Cell Biochem. 2013;381(1-2):139-144.

51. Dahmani R, Just PA, Perret C. The Wnt/ $\beta$-catenin pathway as a therapeutic target in human hepatocellular carcinoma. Clin Res Hepatol Gastroenterol. 2011;35(11):709-713.

52. Xu MX, Zhao L, Deng C, et al. Curcumin suppresses proliferation and induces apoptosis of human hepatocellular carcinoma cells via the wnt signaling pathway. Int J Oncol. 2013;43(6):1951-1959.

53. Li ZQ, Ding W, Sun SJ, et al. Cyr61/CCN1 is regulated by Wnt/betacatenin signaling and plays an important role in the progression of hepatocellular carcinoma. PloS One. 2012;7(4):e35754.

54. Feng P, Wang B, Ren EC. Cyr61/CCN1 is a tumor suppressor in human hepatocellular carcinoma and involved in DNA damage response. Int J Biochem Cell Biol. 2008;40(1):98-109.

55. Liu J, Ding X, Tang J, et al. Enhancement of canonical Wnt/betacatenin signaling activity by $\mathrm{HCV}$ core protein promotes cell growth of hepatocellular carcinoma cells. PloS One. 2011;6(11):e27496.

56. Tsao CM, Yan MD, Shih YL, et al. SOX1 functions as a tumor suppressor by antagonizing the WNT/beta-catenin signaling pathway in hepatocellular carcinoma. Hepatology. 2012;56(6):2277-2287.

57. Yang T, Cai SY, Zhang J, et al. Kruppel-like factor 8 is a new Wnt/betacatenin signaling target gene and regulator in hepatocellular carcinoma. PloS One. 2012;7(6):e39668.

58. Xu J, Zhu X, Wu L, et al. MicroRNA-122 suppresses cell proliferation and induces cell apoptosis in hepatocellular carcinoma by directly targeting Wnt/beta-catenin pathway. Liver Int. 2012;32(5):752-760.

59. Zhang X, Yang Y, Liu X, et al. Epigenetic regulation of the Wnt signaling inhibitor DACT2 in human hepatocellular carcinoma. Epigenetics. 2013:8(4)

60. Wolfe A, Thomas A, Edwards G, Jaseja R, Guo GL, Apte U. Increased activation of the Wnt/beta-catenin pathway in spontaneous hepatocellular carcinoma observed in farnesoid $\mathrm{X}$ receptor knockout mice. J Pharmacol Exp Ther. 2011;338(1):12-21.

61. Kaur P, Mani S, Cros MP, et al. Epigenetic silencing of sFRP1 activates the canonical Wnt pathway and contributes to increased cell growth and proliferation in hepatocellular carcinoma. Tumour Biol. 2012;33(2): $325-336$. 
62. Qin X, Zhang H, Zhou X, Wang C, Zhang X, Ye L. Proliferation and migration mediated by Dkk-1/Wnt/beta-catenin cascade in a model of hepatocellular carcinoma cells. Transl Res. 2007;150(5):281-294.

63. Kwack MH, Hwang SY, Jang IS, et al. Analysis of cellular changes resulting from forced expression of Dickkopf-1 in hepatocellular carcinoma cells. Cancer Res Treat. 2007;39(1):30-36.

64. Fatima S, Lee NP, Tsang FH, et al. Dickkopf 4 (DKK4) acts on Wnt/ beta-catenin pathway by influencing beta-catenin in hepatocellular carcinoma. Oncogene. 2012;31(38):4233-4244.

65. Ding Z, Qian YB, Zhu LX, Xiong QR. Promoter methylation and mRNA expression of DKK-3 and WIF-1 in hepatocellular carcinoma. World $J$ Gastroenterol. 2009;15(21):2595-2601.

66. Yang B, Du Z, Gao YT, et al. Methylation of Dickkopf-3 as a prognostic factor in cirrhosis-related hepatocellular carcinoma. World J Gastroenterol. 2010;16(6):755-763.
67. Tao YM, Liu Z, Liu HL. Dickkopf-1 (DKK1) promotes invasion and metastasis of hepatocellular carcinoma. Dig Liver Dis. 2013;45(3): 251-257.

68. Yamabuki T, Takano A, Hayama S, et al. Dikkopf-1 as a novel serologic and prognostic biomarker for lung and esophageal carcinomas. Cancer Res. 2007;67(6):2517-2525.

69. Shen Q, Fan J, Yang XR, et al. Serum DKK1 as a protein biomarker for the diagnosis of hepatocellular carcinoma: a large-scale, multicentre study. Lancet Oncol. 2012;13(8):817-826.

70. Yang H, Chen GD, Fang F, et al. Dickkopf-1: as a diagnostic and prognostic serum marker for early hepatocellular carcinoma. Int J Biol Markers. 2013;28(3):286-297.

\section{Publish your work in this journal}

The Journal of Hepatocellular Carcinoma is an international, peerreviewed, open access journal that offers a platform for the dissemination and study of clinical, translational and basic research findings in this rapidly developing field. Development in areas including, but not limited to, epidemiology, vaccination, hepatitis therapy, pathology and

\section{Dovepress}

molecular tumor classification and prognostication are all considered for publication. The manuscript management system is completely online and includes a very quick and fair peer-review system, which is all easy to use. Visit http://www.dovepress.com/testimonials.php to read real quotes from published authors.

Submit your manuscript here: http://www.dovepress.com/journal-of-hepatocellular-carcinoma-journal 